Stoa

Vol. 1, No. 1, 2010, pp. 5-19.

ISSN en trámite.

\title{
CUESTIONES FILOSÓFICAS ACERCA DEL DARWINISMO
}

\author{
JACOB BUGANZA \\ Instituto de Filosofía \\ Universidad Veracruzana \\ jbuganza@uv.mx
}

RESUMEN: El autor propone tres temas filosóficos relacionados con el darwinismo. El primero se refiere al concepto de creatio ex nihilo; el autor sostiene que el concepto de creatio ex nihilo es estrictamente teológico y por ello rebasa a la ciencia experimental. Empero, sugiere que se da el diálogo entre teología y ciencia experimental a través de la filosofía. El segundo tema se concentra específicamente al darwinismo social. Aquí el autor realiza una crítica a partir de la antropología y la ética debido a las inconsistencias que encuentra en dicha postura. Finalmente, el autor prosigue la senda de la ética y el darwinismo y sostiene el peligro que la genética juega en la actualidad si se le entiende como una evolución autodirigida.

PALABRAS CLAVE: Darwinismo, darwinismo social, ética y antropología.

SUMMARY: The author proposes three philosophical subjects related to darwinism. The first one refers to the concept of creatio ex nihilo; in this case, the author argues that the concept is strictly theological and thus surpasses experimental science. However, he suggests that philosophy may mediate the dialog between the two. The second subject centers on social darwinism. In this respect, the author makes a criticism from anthropology and ethics on the basis of the inconsistencies he finds in such position. Finally the author continues on the path of ethics and darwinism and warns of the danger in genetics if it is to be judged as self-directed evolution.

KEY WORDS: Darwinism, social Darwinism, ethics and anthropology.

\section{Introducción}

Hay razones para sostener que la teoría darwiniana no es solamente una posición biológica en la que el ser humano queda al margen. Por el contrario, 
puede afirmarse, mediante un simple razonamiento, que cualquier teoría que tenga por cometido hablar acerca de los mecanismos con los cuales se origina, desarrolla, decrece y desaparece la vida tiene como parte de su estudio al ser humano, aunque no lo sea de modo temático en principio. Y la prueba de la conclusión es todavía más simple: el ser humano es un viviente o ser orgánico (unidimensionalmente hablando), objeto material de estudio que se descubre en El origen de las especies o la preservación de las razas favorecidas en la lucha por la vida, que es la obra más reconocida de Charles Darwin. Tal vez la manera con la cual el hombre pueda quedar al margen de este asunto, aunque no del todo, es afirmando, previamente, que el hombre es algo más que naturaleza, es decir, que en cierto modo hay algo en él que escapa a las clasificaciones de los naturalistas. Pero no es el caso de este naturalista inglés.

\section{Primera cuestión: evolucionismo y creacionismo}

Las relaciones entre ciencia, religión y filosofía son un tópico ampliamente discutido hoy, aunque de algún modo es un tema que haya transitado a lo largo de toda la historia de las ideas en occidente. El asunto se aprecia desde los griegos y pasa por la patrística, de manera especial en san Agustín, y prosigue durante la escolástica y la modernidad. Cada momento y cada autor tienen sus propias teorías acerca de las relaciones que se establecen entre una y otra, y los campos epistémicos a los que se refiere cada cual por su parte. Pero parece que, al menos desde cierta tradición, puede afirmarse que hay ciertas cuestiones que no caen dentro del análisis científico, entendiendo por tal análisis lo empírico o lo verificable. Pero esto último es algo heredado del empirismo y de la observación minuciosa de los fenómenos, y eso se aprecia en cierto grado en la ciencia inglesa, de la que Darwin es un digno representante. El caso es no transgredir los límites de una, pues los resultados se extrapolan irremediablemente y dan pauta para otras tesis que, en principio, no parecen ser muy provechosas. Hay, pues, cuestiones que escapan al terreno empírico por factores diversos. Caen más bien dentro del análisis de la filosofía y de la religión.

Una tesis cautelosa o moderada sobre este asunto, expresada con toda sencillez, es que los conceptos de creatio ex nihilo y evolución pertenecen a dos planos distintos, aunque complementarios desde una visión holística. El primer 
concepto corresponde al plano teológico y no puede someterse a experimentación. El segundo se ubica en el plano científico, y no por ello tiene licencia para suprimir al otro. El juicio implacable de la historia puede pasar factura a futuro a los evolucionismos reduccionistas o cientificistas (no todos lo son, sin duda). ${ }^{1}$ La historia se vuelve juez, como dice Ratzinger a propósito de la Iglesia: "Las humillaciones de la historia se derivan precisamente de que en un momento determinado el hombre creyó que debía asumir plenos poderes y considerar como única y verdadera realidad solamente sus propias empresas" (Ratzinger 2005a, p. 95). En efecto, la lógica, y la historia como magistra vitae, enseñan que hay que distinguir los planos. La lógica enseña a distinguir, y lo primero que debe distinguirse son los planos conceptuales. Por ello uno no puede invadir al otro sin ningún género de dificultad. Ahora bien, si se retoma la tesis de Mariano Artigas (2000), el puente entre la ciencia y la religión puede ser la filosofía.

La filosofía no estudia los mecanismos de la evolución, pues tal estudio pertenece propiamente a la ciencia. Lo que hace la filosofía en torno a la evolución es reflexionar acerca de su significado; analiza sus condiciones de posibilidad y sus implicaciones (Artigas 1988, p. 262). Tomando como base la tesis del filósofo de la ciencia Mariano Artigas, hay al menos tres condiciones de posibilidad para la evolución. En primer lugar, la evolución requiere que existan entidades y unas leyes básicas que puedan servir como base de la evolución; en segundo término, estas entidades y leyes deben ser muy específicas, pues las virtualidades de los entes deben posibilitar la formación de nuevas entidades con nuevos tipos de organización; finalmente, en cada fase evolutiva han debido darse las condiciones necesarias para actualizar las virtualidades. Por eso escribe este autor que, finalmente, las teorías evolucionistas "Se apoyan en unos supuestos, o condiciones de posibilidad: la existencia de una materia y de unas leyes muy específicas, cuyas virtualidades han permitido la sucesiva producción de toda una serie de organismos que forman una escala enormemente variada" (ibídem, p. 263).

Actualmente se acepta el hecho de la evolución, mas no hay unanimidad en los conceptos que la explican. Desde el punto de vista del entrelazamiento entre dinamismo y estructuración, "La evolución aparece como un conjunto de

${ }^{1}$ Con respecto al concepto de "ciencia experimental", vale la pena consultar Artigas 1999 y 2000, pp. 169-171. 
procesos morfogenéticos en los diferentes niveles naturales. En cada fase de la evolución existen unas virtualidades que se actualizan en función de los factores que intervienen; se producen nuevos tipos de organización que poseen nuevos tipos de dinamismos y virtualidades, cuyo despliegue y actualización producen, a su vez, otros niveles de organización, y así sucesivamente. Todo ello puede ser contemplado como el despliegue de una información original que, en sucesivos niveles de organización, da lugar a nuevas pautas informacionales de complejidad creciente" (ibídem, p. 257). El concepto de virtualidad puede ser de mucha utilidad desde el punto de vista filosófico y científico. Filosóficamente, los entes tienen virtualidades que pueden actualizarse, aunque no hay acuerdo científico en qué motiva dichas actualizaciones. Sobre esto y sobre el origen de la vida, que implica el problema de cómo es que de lo inerte surge un nuevo estrato ontológico, la ciencia puede tener incumbencia. Pero ello no invita a que se cierre en sí misma haciendo caso omiso de otros saberes.

Redondeando la idea anterior, el hecho de la evolución es, pues, aceptado generalmente. Cambian las perspectivas desde las cuales se explica tal proceso. Lamarck propone el transformismo mediante la herencia de caracteres adquiridos; Darwin ofrece como explicación la selección natural; el neodarwinismo plantea la combinación de mutaciones genéticas al azar y selección natural, por no hablar del "neutralismo" de Motoo Kimura, el "saltacionismo" de Jay Gould y Niles Eldredge, etcétera (ibídem, pp. 260-262). Pero sobre lo que la ciencia no tiene una incumbencia directa es sobre el concepto de creación, de la creatio ex nihilo, que pertenece al plano propiamente religioso. No hay contradicción entre la evolución y la creación, pues se refieren a dimensiones distintas. En conclusión, pueden aceptarse ambas.

\section{Segunda cuestión: darwinismo social, antropología y ética}

El darwinismo es, como bien se sabe, una teoría que explica la evolución de acuerdo a los conceptos de "selección natural" y "supervivencia del más apto". No implica ninguna sorpresa afirmar que la teoría de Charles Darwin no es otra cosa que, en principio, una teoría surgida en el seno de la biología. Además, la teoría de la evolución de Darwin no es original en cuanto al concepto evolución, ${ }^{2}$ pues hay varios autores previos que plantean el concepto de evolu-

${ }^{2}$ Cfr. Artigas 2000, p. 129 
ción biológica. Lo que se considera original en él es el concepto de selección natural, pues a partir de tal selección se da la supervivencia del más apto (pero aún así hay controversia sobre este asunto). ${ }^{3}$ Hay quienes afirman que el concepto de "pangénesis" sería lo más original de Darwin. Sobre este concepto, ${ }^{4}$ la selección natural es un mecanismo de la evolución, y "Opera silenciosamente bajo todo el proceso evolutivo, haciendo que los mejor adaptados sobrevivan y distribuyan sus características favorecidas entre la población. El darwinismo es, pues, la teoría de la evolución por selección natural" (Hoyos 2001, p. 19). Empero, la expresión que ha venido a ser "cara" a la teoría darwinista es la de "supervivencia del más apto", que, según Hoyos, ${ }^{5}$ Darwin tomó prestada de Herbert Spencer, con lo cual su vinculación se dio por sentada. ${ }^{6}$ Hay una mutua retroalimentación entre Darwin y Spencer, pues las ideas políticas de este último se presentan sustentadas, al menos en apariencia, en la teoría evolucionista de Darwin, y son precisamente tales ideas políticas lo que se denomina "darwinismo social" (Hoyos 2001, pp. 19-20).

Con respecto al darwinismo, las expresiones "selección natural" y "supervivencia de los más aptos" connotan prácticamente lo mismo, sólo que la primera hace referencia a que la naturaleza selecciona, de manera análoga como lo hace el hombre, qué individuo y qué especie sobrevive de acuerdo a las variables que han adquirido el individuo o especie a lo largo del tiempo (variaciones que pueden dar origen a nuevas especies, sin duda); por su parte, la supervivencia de los más aptos hace referencia a que son precisamente los más capaces los que sobreviven. Por eso escribe Darwin: "A esta conservación de las diferencias y variaciones individualmente favorables y a la destrucción de las que son perjudiciales la he llamado yo selección natural o supervivencia de los más aptos" (ibídem, p. 155). La selección natural es incomensurablemente superior a los esfuerzos del hombre en la selección artificial, análogamente a como son las obras de arte con respecto a las obras de la naturaleza (ibídem, p. 131); además, "El hombre selecciona solamente para su propio bien; la naturaleza lo hace sólo para el bien del ser que tiene a su cuidado" (ibídem, p. 158). Por otro lado, esta postura darwiniana mantiene una par de tesis tradi-

${ }^{3}$ Cfr. Sandín 2000, pp. 28 y 30.

${ }^{4}$ Cfr. Noguera y Ruiz 2005.

${ }^{5}$ Vid. ibídem.

${ }^{6}$ Cfr. Darwin 2008, p. 131. 
cionales que se remontan al menos a Aristóteles. Estas tesis son la tendencia del individuo a mantenerse en la existencia individual, que no es otra cosa que la supervivencia, y el mantenimiento de la especie, lo cual, a diferencia de la biología aristotélica, donde las especies son formas estables (al igual que en la visión platónica), la darwiniana pugna por la modificación de las mismas en función de variaciones. Como sea, la naturaleza selecciona lo bueno y rechaza lo malo de tales variaciones en los entes, con tal de que sobrevivan unos y otros desaparezcan, es decir, que los seres más capaces subsistan y que los menos se desvanezcan, y esto se da precisamente por las variaciones: "Metafóricamente, puede decirse que la selección natural está buscando cada día y cada hora por todo el mundo las más ligeras variaciones; rechazando las que son malas; conservando y sumando todas las que son buenas; trabajando silenciosa e insensiblemente, cuando quiera y dondequiera que se ofrece la oportunidad, por el perfeccionamiento de cada ser orgánico en relación con sus condiciones orgánicas e inorgánicas de vida" (ibídem, p. 159).

Darwin, como buen naturalista, goza de una pluma muy ad hoc para describir los fenómenos que se le presentan o imagina. Por ello da ejemplos muy creativos sobre la selección natural. Uno de ellos es el de los lobos: "Los lobos más veloces y más ágiles tendrían mayores probabilidades de sobrevivir y de ser así conservados o seleccionados, siempre que conservasen fuerza para dominar a sus presas en esta o en otra época del año, cuando se viesen obligados a apresar otros animales" (ibídem, p. 159). Desde esta perspectiva, es más probable que sobreviva el lobo que ha adquirido una mayor velocidad y agilidad, pues tales variaciones le brindan una cierta ventaja sobre otros competidores por la vida, es decir, sobre lobos con menos variaciones en dicha dirección (llamada, por Darwin, "dirección debida"; cfr. ibídem, p. 184) o sobre otros depredadores: "La forma primitiva pronto sería suplantada por la forma modificada, a causa de la supervivencia de los más aptos" (ibídem, pp. 170-171). Esta "forma modificada" puede tomar mucho tiempo, desde el punto de vista humano, para desatarse. Por eso, Darwin considera que "La selección natural desterrará la creencia de la creación continua de nuevos seres orgánicos o de cualquier modificación grande y súbita en su estructura" (ibídem, p. 176). Esta última afirmación puede implicar ciertas dificultades y, aunque Darwin no hable de ello en El origen de las especies, puede aplicarse al caso del ser humano, 
cuya evolución, de acuerdo con los descubrimientos paleo-antropológicos impulsados especialmente a partir de mediados del siglo XIX y durante todo el $\mathrm{XX}$, ha tenido precisamente esa característica. Por ejemplo, el homo sapiens ha desbancado o suplantado a otros homínidos, como el homo neanderthalis. Cargando un poco las tintas en dirección al "principio de divergencia", que es un principio productor de diferencias, se observa que "Las razas se separan, por sus caracteres, unas de otras y también del tronco común” (ibídem, p. 195). Dice más adelante: "Lo que se aplica a un animal se generaliza en todo tiempo a todos los animales" (ibídem, p. 196). ¿Podría esto ser aplicado sin dificultad al caso humano, debido a la unidimensionalidad orgánica que presenta la antropología darwiniana?

Es perfectamente legítimo que la filosofía se ocupe del proceso evolutivo que ha concluido en el ser humano, pues en ello se juega en buena medida el concepto de hombre. Darwin no examina este problema de forma temática en El origen de las especies, sino que lo hace en una obra posterior (de 1871) cuyo título es El origen del hombre y la selección sexual. Ahí el naturalista inglés afirma que, desde el punto de vista de las facultades intelectuales, no existe ninguna diferencia fundamental entre el ser humano y los mamíferos superiores. ${ }^{7}$ En realidad se trata sólo de una diferencia de grado, y no de especie. Ahora se sabe que otros mamíferos superiores, como el chimpancé, tienen en común con el hombre cerca de un $99 \%$ de material genético, y que ambos tienen un ancestro común. No hay duda de que hay continuidad entre los mamíferos superiores y el hombre; es más, hay continuidad entre toda la escala de entes y el hombre, lo cual es algo que ya los antiguos y medievales observaron al expresar metafóricamente que el hombre es un microcosmos. Darwin acierta en que hay continuidad entre los mamíferos superiores y el hombre; pero también hay que aceptar que las facultades humanas son reales y que no se encuentran en los demás animales. "Basta pensar - dice Artigas (1998, p. 271) - en el conocimiento intelectual, la capacidad de autorreflexión, la capacidad de argumentar, el sentido de la evidencia y de la verdad, la libertad, los valores éticos". ${ }^{8}$

7 "No hay diferencia esencial en las facultades del hombre y los mamíferos superiores" (Darwin 1989, p. 71). La única diferencia, desde su postura, es el lenguaje "articulado" ( $c f r$. pp. 90ss).

${ }^{8}$ Desde un punto de vista filosófico, si no hay diferencia más que de grado; es decir, si el hombre no pasa de ser un mero organismo en su definición, diluye la propia experiencia de otras dimensiones que no se someten a la experimentación. 
Basta retomar un solo argumento de Darwin sobre este asunto. En El origen del hombre trae a colación una de las diferencias entre el ser humano y otros organismos que resulta paradigmática: la abstracción y los conceptos generales o universales. Escribe: "Obsérvese que al ver de lejos un perro a otro percibe en abstracto que en efecto es un perro, y si no, véase cómo al acercarse más cambia completamente de aspecto si advierte que es amigo" (Darwin 1989, p. 88). Su argumentación es muy deficiente, y con dos observaciones se alcanza a ver por qué. En primer lugar, afirma gratuitamente que el perro que percibe al otro lo hace "en abstracto"; no hay nada que lleve a esa conclusión. En segundo lugar, afirma que el perro perco (ibídem), es "amigo", lo cual no hace referencia directa a la potencia abstractiva del hombre, sino a la memoria, que es una facultad orgánica; de ahí que su argumento no se siga en absoluto. Por eso y otras observaciones gratuitas, no puede aceptarse la tesis que asevera que los animales tienen cierto poder de raciocinio, pues, de acuerdo con Darwin, "Se los ve a menudo detenerse, reflexionar y decidirse" (ibídem, p. 80).

Ahora bien, el darwinismo social, de cuño marcadamente spenceriano, aunque no siempre negado, como se verá, por el propio Darwin (como buen victoriano), concibe a la especie humana como un ente completamente orgánico y, por lo tanto, sometido al mismo proceso evolutivo al cual se subordinan las otras especies. Esta idea no es del todo nueva, pues se ve plasmada, en la Inglaterra de los siglos XVIII y XIX, por diversos autores. Por ejemplo, es el caso del economista Thomas Malthus, "Quien convenció a su primer ministro de que en las 'casas de trabajo' destinadas a los indigentes, los sexos deberían estar separados”, en razón del aumento de población, el cual lleva inevitablemente a una lucha por la supervivencia en vistas a adquirir el alimento disponible. Por su parte, Adam Smith, según Sandín, fue quien enterró la idea del precio justo, "Ya que desde entonces los precios estarían regulados por la 'ley' de la oferta y la demanda”. Finalmente, Spencer, como se dijo, acuña en su texto $L a$ estática social el concepto de "supervivencia del más apto", en donde opina que "El intento de ayudar a los pobres era un entorpecimiento de las Leyes naturales que se regían por la competición” (Cfr. Sandín 2000, pp. 36-37). Spencer se compromete por completo con el laissez faire, y por ello el Estado no tiene por qué intervenir bajo ninguna circunstancia en la lucha a favor de los menos aptos, como los pobres: "Ciegos al hecho de que bajo el orden natural de 
las cosas la sociedad está eliminando sus miembros enfermos, imbéciles, lentos, vacilantes y sin fe, estos hombres irreflexivos, aunque bienintencionados, abogan por una interferencia que no sólo detiene el proceso purificador, sino que incluso aumenta el vicio: promueve completamente la multiplicación de los inconscientes e incompetentes ofreciéndoles un sustento inagotable y desanima la multiplicación de los competentes y prudentes aumentando la dificultad de mantener una familia". ${ }^{9}$ Por su parte, en una respuesta al jurista Heinrich Fick, "Darwin comenta lo interesante que le había parecido el ensayo elaborado por el citado jurista, en el que sugería que el gobierno debería imponer restricciones al matrimonio de los individuos 'no aptos' para el servicio militar. También utilizaba el darwinismo para oponerse a los intentos de crear una igualdad socioeconómica, "porque esto puede beneficiar a los débiles y conducir a la degeneración'” (Sandín 2000, p. 39).

Todo esto no es otra cosa que expresión de que unos individuos, miembros de la especie, son más aptos para sobrevivir que otros. En términos generales esto es cierto, pues nadie puede negar que al interior de las especies unos individuos son más capaces de sobrevivir que otros. Es el caso de una empresa económica constituida por seres humanos: hay quienes son más aptos para adaptarse a la empresa que otros, y son los primeros quienes mantienen la supervivencia, es decir, su trabajo. Pero de ahí a afirmar que, en el contexto de la supervivencia humana, es decir, de la supervivencia de la especie, haya unos que deban sobrevivir en lugar de otros en razón de su diferencia esencial (acumulada por "pequeñas diferencias" que se vuelven esenciales), hay un trecho muy amplio, pues pone en riesgo el concepto de mismo de especie. De acuerdo con la lógica clásica, todos los entes que pertenecen al mismo género y tienen la misma diferencia específica, pertenecen a la misma especie. En esto hay igualdad esencial. Pero también hay diferencias, que se expresan mediante el predicable accidente. Sin embargo, si dentro de la especie hay diferencias esenciales, entonces la especie deja de existir como tal pues se convierte en un nuevo género. Este es el razonamiento para hablar de las distintas razas humanas: es indudable que las hay, pero es diferente concebir que corresponden a una diferencia esencial que a una accidental, pues lo primero lleva a clasificar a algunas razas como "inferiores" y "superiores",

${ }^{9}$ Citado por Ruse 2007, p. 204. 
como de hecho menciona Darwin en El origen del hombre (Darwin 1989, pp. $70-71)$.

Hay infinidad de casos que ejemplifican este asunto. En su artículo sobre el darwinismo social, Sandín trae a colación algunos de ellos. William Shockley, de la Universidad de Standford, propuso - narra Sandín - una ley pidiendo la esterilización de las personas cuyo coeficiente intelectual fuera inferior a 100; propuso iniciar este programa con personas dependientes de la seguridad social estadounidense a cambio de una compensación económica. William Saxbee, fiscal de los Estados Unidos, declaró que los genes socialistas tienden a agruparse en familias judías. Apoyándose en Rose, Sandín afirma que el manual del joven hitleriano, de 1937, está plagada de darwinismo y genética, haciendo uso de estos conocimientos como justificación científica del holocausto (Sandín 2000, pp. 43-44).

Cabe enunciar en este punto, aunque sea sucintamente, algunas interrogantes más al darwinismo en general y al darwinismo social en particular. La primera es que la noción de la "superviviencia del mejor dotado" parece contener cierta circularidad, en el sentido de que no explica lo que se propone. Tenzin Gyatso, en un análisis muy concienzudo acerca de los puntos convergentes y divergentes entre la teoría de la evolución darwiniana y el budismo, encuentra también esta circularidad cuando afirma: "La teoría de la selección natural sostiene que, de las mutaciones aleatorias que ocurren en los genes de una especie determinada, es más probable que se impongan aquellas que garantizan mayores probabilidades de supervivencia. Sin embargo, la única manera de verificar esta hipótesis es observando las características de las mutaciones supervivientes. En cierto sentido, pues, afirmamos lo siguiente: Puesto que estas mutaciones genéticas han sobrevivido, son las que tenían mayores probabilidades de sobrevivir" (Dalai Lama 2007, p. 136).

La segunda cuestión es que, si la teoría de la evolución se fundamenta en la observación de los fenómenos naturales, tal parece que dicha observación llega a ser reduccionista. En efecto, en la naturaleza no sólo se observa el hecho de que los individuos y las especies buscan la supervivencia ganando la competencia o con sus semejantes, es decir, con los miembros de su misma especie, o con otras especies. También pueden observarse ciertos comportamientos que, de manera análoga en el ser humano, quien recibe la antonomasia del 
término, pueden ser calificados de "altruistas", a reserva de que se explique recurriendo a la eficacia moral. ${ }^{10}$

Una tercera cuestión, que tal vez sea el problema más grave al que puede orientar un darwinismo social desde el punto de vista de la ética, es que pueda justificarse cualquier acción recurriendo al argumento de que se actúa de cierta forma porque se busca la sobrevivencia. ${ }^{11}$ Esto, en el plano de la ética, es lo que comienza a llamarse "humanismo sin límites" o, como también podría denominarse, "equivocismo ético". ¿En qué consiste tal humanismo o equivocismo? Lluch echa luz al escribir que "Su argumento principal es: ¿por qué no? Todo puede hacerse, no hay bien ni mal, no hay acciones mejores o peores. Nada nos limita"(Lluch 2007, p. 308). Aplicado al caso del darwinismo social, podría complementarse esta idea recurriendo, simplemente, a la guerra natural de la biósfera. Esto es así porque, de acuerdo a las observaciones de Darwin, "Todos los seres orgánicos están sujetos a rigurosa competencia [...] Nada más fácil que admitir de palabra la verdad de la lucha universal por la vida, ni más difícil - por lo menos, así lo he experimentado yo -que tener siempre presente esta conclusión"(Darwin 1987, p. 131). Pero aún hay más si se aplican las siguientes palabras, extraídas del contexto del principio de extinción, al caso del ser humano: "La lucha será, en general, más rigurosa entre las formas que estén más relacionadas entre sí en costumbres, constitución y estructura" (ibídem, p. 206).

En cuarto lugar, si el hombre sólo es un cúmulo de elementos orgánicos, entonces se anularía el concepto de libertad y, consecuentemente, el de responsabilidad quedaría anulado. Miguel Lluch plantea la siguiente interrogante: "De entre las muchas acciones que pueda realizar [el hombre,] ¿̇cuáles son buenas y cuáles malas, cuáles me hacen bueno o malo? Así las decisiones y acciones humanas se caracterizan porque pueden ser calificadas como buenas o malas moralmente y esto independientemente de si alcanzan mis intereses o mis preferencias" (ibídem, p. 297). Si el hombre sólo es orgánico y se diferencia de los mamíferos superiores únicamente en grado, la pregunta que plantea Miguel Lluch no tendría ningún sentido. Esto implica los problemas éticos, pues la libertad aparece como condición necesaria para hablar ellos.

${ }^{10}$ Cfr. Ayala 1989, pp. 256- 262.

${ }^{11}$ Lo cual se asienta, a su vez, en la unidimensionalidad orgánica que promovería una suerte de determinismo físico-químico, que retomaremos unas líneas más abajo. 
Como frecuentemente se afirma, la ética no viene sola, sino que está fundamentada en algo previo: en una visión integral del ser humano, es decir, en una antropología filosófica. Dependiendo de la visión filosófica del hombre que se tenga, dependerá la ética que se construya y se proponga como idea de la vida buena. De aceptarse la antropología darwiniana, la ética se disgregaría.

Ahondando más en los conceptos de la ética, el darwinismo social tiene un desdén muy marcado por el concepto de justicia. Más bien lo aplica a la conveniencia del más apto, pues lo justo sería aquello que es del más fuerte. Y si además se acepta su antropología, entonces no habría responsabilidad alguna ante los actos realizados. Es muy parecido a lo que Maliandi observa con respecto a la ética en la globalización, pues de acuerdo con este autor algunos se cuestionan qué tipo de ética conviene en este asunto, y se responden que una darwinista. Pero el darwinismo social tiende a la disolución de los sistemas morales porque relativiza los medios en orden a la supervivencia: De ahí que, como escribe Maliandi, el darwinismo social "Tiende más bien a una situación precontractual sin código normativo alguno, [por lo que] no puede regir una reflexión moral, ni puede esgrimirse como ética normativa, es decir, como esfuerzo de justificación o fundamentación de normas morales" (Maliandi 2004, p. 78). Pero más allá de lo contractual, el darwinismo social niega cualquier genuinidad del hombre con respecto a todos los demás organismos, por lo que hablar de ética y moralidad sería superfluo.

\section{Tercera cuestión: ética, darwinismo y genética}

Otro escollo interesante es el que puede acaecer al momento de justificar la mejora genética de la especie a partir de un argumento de tipo darwinista: con tal de preservar la especie, podrían modificarse ciertos genes con tal de hacer "superior" a un individuo dentro de la especie. Ciertamente esto tiene ecos de ciencia ficción, pero no debe olvidarse que la ciencia ficción se mueve en el ámbito de lo posible, y lo posible es todo aquello que de alguna u otra manera puede ser. Esto se enmarca en la multiplicidad de posibilidades que se abren desde la clonación hasta la manipulación genética. En ambos casos la posibilidad de alterar la composición genética de las especies es inmensa. Por ello es que la pregunta decisiva es, en este contexto, la siguiente: "¿Hasta dónde debemos llegar en la selección artificial de fetos que poseen características deseadas 
que, se supone, aumentan la inteligencia o la fuerza física"? (Dalai Lama 2007, p. 226). Concomitante a la pregunta anterior, parece que, por un buen tiempo, esta posibilidad de modificar la descendencia será exclusiva de las clases más privilegiadas. Esto podrá ensanchar las desigualdades; puede aumentar la brecha ya presente, pues potenciaría una "desigualdad de naturaleza", por ejemplo, por el aumento de inteligencia, fuerza y otras facultades adquiridas desde el mismo nacimiento (ibídem, p. 227). Esta idea está en consonancia con lo que expresa Darwin acerca de las variaciones (que pudieran llegar a ser genéticas) de los seres orgánicos en su enfrentamiento por la supervivencia: "Debido a esta lucha, las variaciones, por ligeras que sean y cualquiera que sea la causa de que procedan, si son en algún grado provechosas a los individuos de una especie en sus relaciones infinitamente complejas con otros seres orgánicos y con sus condiciones físicas de vida, tenderán a la conservación de estos individuos y serán, en general, heredadas por la descendencia" (Darwin 1989, p. 130). En síntesis, podría desencadenarse una eugenesia sin precedentes.

Todos los conocimientos científicos que brindan las ciencias de la vida y sus consecuentes aplicaciones tecnológicas no son, en realidad, lo más urgente o importante. Hay cuestiones que reclaman mayor atención debido a que, como afirma la ética, hay una relación estrecha entre el conocimiento, el poder que se deriva de éste y la responsabilidad ante los actos que, en el caso de la ciencia, es lo que se llama tecnología o ciencia aplicada. Es el caso de la ingeniería genética, que es, de acuerdo con Ciccone, "El conjunto de intervenciones capaces de aportar modificaciones al patrimonio genético de seres vivos, desde los seres unicelulares al hombre" (Ciccone 2005, p. 224). Por su parte, Ansón sostiene que "Las leyes biológicas que han presidido la evolución de las especies pueden quedar alteradas por la introducción de un nuevo factor o variable: la capacidad del hombre de ciencia de poder dirigir la evolución mediante ingeniería genética, tanto de otros seres vivos como del mismo ser humano" (Ansón 1988, p. 165). Como es evidente, la ingeniería genética plantea nuevos desafíos éticos. La ética debe sostener que no todo lo que es técnicamente posible es lícito éticamente. Los nuevos aportes de la ingeniería genérica requieren una reflexión muy profunda sobre su legitimidad ética. La reflexión ética debe ser, pues, el paso previo. 
Poco se está reflexionando éticamente acerca de la gran carga de responsabilidad que conlleva el mayor conocimiento y poder de la ciencia. Pero también hay que tener en cuenta que, por otro lado, es igualmente necesario acrecentar el caudal cognoscitivo para comprender con mayor profundidad los alcances e impactos de las aplicaciones tecnológicas. La ética debe reflexionar seriamente sobre estos dos aspectos cruciales. En este sentido, ¿no sería mejor ser precavidos en estos asuntos, pues el hombre tomar caminos evolutivos que lo lleven por sendas infranqueables, nocivas y perjudiciales para la mayoría de los miembros de la especie? ¿No valdría más ser precavidos y reflexionar suficientemente sobre los actos que la especie humana puede desencadenar a través de la ingeniería genética? Tal vez la ética está llegando tarde a este asunto, pues la aplicación de las nuevas tecnologías genéticas está siendo inminente.

\section{Conclusión}

La teoría darwinista, si se examina desde un punto de vista filosófico, entraña una gran cantidad de preguntas que motivan la reflexión por los fundamentos últimos. Los temas aquí tratados están interconectados debido a que el darwinismo es, al parecer, una visión totalizadora. De origen es una teoría científica, pero puede llegar a distenderse y convertirse en una filosofía, aunque sea en sentido laxo. Por eso es que Sandín, al referirse al darwinismo social, asienta: "No parece riguroso seguir argumentando que el llamado darwinismo social sea producto de una deformación o una mala interpretación de la teoría darwiniana, porque, en definitiva, es la interpretación (y en su caso, aplicación ) literal de lo único totalmente claro y concreto de la gran obra de Darwin: el título" (Sandín 2000, p. 45).

Se ha visto en primer lugar que la evolución no está pugna con el concepto religioso de creatio ex nihilo. Pueden aceptarse uno y otro, pues la creación se refiere a un acto que no es empíricamente verificable, mientras que la ciencia pretende verificar sus propuestas aunque sea partir de vestigios y no de la repetición del fenómeno o experimentación. En segundo lugar se expuso brevemente la teoría darwinista y su aplicación al campo social, donde se plantean una serie de dificultades que entrañan a la antropología filosófica y a la ética. Finalmente, en un campo que está por abrirse que es la ingeniería genética, 
la ética debe poner más atención en la reflexión acerca de las consecuencias y responsabilidades que puede implicar el uso de estos nuevos conocimientos, los cuales con toda seguridad cambiarán la fisionomía de la humanidad y la llevarán por senderos desconocidos.

\section{Referencias}

Ansón, F., 1988, Se fabrican hombres. Informe sobre la genética humana, Rialp, Madrid.

Artigas, M., 2000, La mente del universo, Eunsa, Pamplona.

- 1999, Filosofía de la ciencia experimental, Eunsa, Pamplona.

, 1998, Filosofía de la naturaleza, Eunsa, Pamplona.

Ayala, F., 1989, La naturaleza inacabada, Salvat, Barcelona.

Ciccone, L., 2005, Bioética. Historia, principios, cuestiones, Palabra, Madrid.

Dalai Lama, 2007, El universo en un solo átomo, Debolsillo, México.

Darwin, Ch., 2008, El origen de las especies, Universidad Veracruzana, Xalapa. , 1989, El origen del hombre, Edaf, Madrid.

Hoyos, D., 2001, Ética naturalizada: educación, naturaleza y moralidad, Universidad de Caldas, Manizales.

Lluch, M., 2007, "El drama de una ética sin límites", en Actas del VI Simposio Internacional fe cristiana y cultura contemporánea, Universidad de Navarra, Pamplona.

Maliandi, R., 2004, Ética: dilemas y convergencias. Cuestiones éticas de la identidad, la globalización y la tecnología, Biblos, Buenos Aires.

Noguera, R. y R. Ruiz, 2005, "Pangénesis y vitalismo científico", Asclepio. Revista de Historia de la medicina y de la ciencia, vol. 57, no. 1, pp. 219-236.

Ratzinger, J., 2005 “'Por qué permanezco en la Iglesia?”, en Ratzinger y Balthasar 2005, pp. 83-110.

Ratzinger, J. y H.U. von Balthasar, 2005, ¿ंPor qué soy todavía cristiano? ¿ Por qué permanezco en la Iglesia?, Sígueme, Salamanca, 2005.

Ruse, M., 2007, ¿ ¿ Puede un darwinista ser cristiano? La relación entre ciencia y religión, Siglo XXI, México.

Sandín, M., 2000, "Sobre una redundancia: el darwinismo social", Asclepio. Revista de Historia de la medicina y de la ciencia, vol. 52, no. 2, pp. 27-50. 